\title{
Low risk infants clinically monitored in well newborn nursery who later required transfer to nicu for further care
}

\begin{abstract}
Background: Perinatal-Neonatal care (PNC) has changed and improved over the years. Change has occurred in the length of hospital stay and the unit to which infants are admitted. There is no longer a transitional nursery (TN) where low risk infants who did not belong in either the well-baby nursery (WBN) or NICU would be observed. Infants in the WBN identified to be sick enough to require NICU care were evaluated and the findings were discussed with the NICU attending and the infant's parents prior to transfer. Infants transferred to the NICU are discussed monthly as a project of improvement (PI) for residents.
\end{abstract}

Methods: We conducted a retrospective descriptive study of neonates who required a transfer from the WBN to NICU from January 2005 to December 2014. Data collected from the medical records and QI reports included: maternal, fetal medical issues, all the birth parameters of the infants on arrival to $\mathrm{WBN}$, and follow up care with reason for transfer which occurred within 72 hours.

Results: Over the study period of 10 years, we had $625(16 \%)$ infants who required transfer from the WBN to NICU out of the total admissions (3860). The gestational age ranged between 34 and 42 weeks and the mean gestational age was 38.8 weeks \pm 1.42 weeks. The birth weight was between 1940 and $5285 \mathrm{~g}$ and the mean weight was $3286 \mathrm{~g} \pm 589.6 \mathrm{~g}$. The mean Apgar scores were 8.7, 8.8 and 8.9 at first, fifth and tenth minutes respectively. The mean time of transfer was 9 hours and it ranged between 1 and 159 hours. The average length of stay in the NICU was 5 days and it ranged between 1 and 78 days. Sixteen out of $625(2.6 \%)$ infants required a transfer to a tertiary care center (TCC). All infants did well with a good outcome. One infant out of 625 died in our own hospital before transfer to TCC due to a severe pulmonary stenosis

Conclusion: The decision to admit low risk infants to WBN is to facilitate mother infant bonding, breastfeeding and to decrease overcrowding in NICU while providing continuous medical and nursing care in WBN. 16\% of our total 3860 NICU admissions are from transfers while our NICU average census and length of stay remained constant throughout the study period. When assessing an infant in WBN for a transfer in NICU, special attention should be given for assessment of maternal and infant medical issues which threaten the neonatal outcome with particular attention to cardiorespiratory status.

Keywords: Transfer, Nursery, NICU, Low risk infants, Respiratory distress, Congenital heart disease
Volume 7 Issue 6 - 2017

\author{
Tarik Zahouani, Arkar Ye Hlaing, Hoda \\ Karbalivand, Juan Guillen-Hernandez, \\ Benamanahalli Rajegowda \\ Department of Pediatrics, Lincoln Medical and Mental Health \\ Center, USA
}

Correspondence: Tarik Zahouani, Department of Pediatrics, Lincoln Medical and Mental Health Center, 234E, I49 St. Bronx NY 1045I, USA, Tel 7|8-579-5030, Email TarikZahouani@gmail.com

Received: August 15, 2017 | Published: September 26, 2017

\section{Introduction}

Perinatal-Neonatal care (PNC) has changed and improved over the years. Change has occurred for infants in the length of their hospital stay and the unit to which they are admitted. There is no longer a transitional nursery $(\mathrm{TN})$ where low risk infants (late preterm, infant of diabetic mother, preterm premature rupture of membranes, infants of toxemic mothers and infants with minor congenital anomalies) who did not belong in either the well-baby nursery (WBN) or NICU would be observed. Infants in the WBN who were identified to be sick enough to require NICU care were clinically evaluated and the findings were discussed with a NICU attending as well as the infant's parents before they were transferred. Infants that were transferred to the NICU are discussed monthly as part of a project of improvement (PI) for residents to assess quality improvement (QI, as a part of a learning process for the trainees and the infant's outcome in the NICU.

\section{Methods}

Our institution is located in an urban area serving a predominantly minority and immigrant population of low socio-economic status.
The hospital has data of a median income of $\$ 13,776 /$ year with a population consisting of a majority of Hispanic patients and a minority of African American patients. Many women do not seek prenatal care early enough to care for themselves and for their fetus during pregnancy with documented multiple medico social issues affecting the mother, the fetus and the newborn at birth. We conducted a retrospective descriptive study of neonates who required a transfer from the WBN to NICU from January 2005 to December 2014 for medical and surgical management. Data collected from the medical records and QI reports included: maternal, fetal medical issues, all the birth parameters of the infants on arrival to WBN, and follow up care with reason for transfer which occurred within the first hours of life. At each instance, parents were informed of the reason for transfer, condition of the infant and their visitation to the NICU since they were concerned of the baby's condition.

\section{Results}

Over the study period of 10 years, we had $625(16 \%)$ infants who required transfer from the WBN to NICU out of the total admissions (3860). The gestational age ranged between 34 and 42 weeks and the 
Table Continued..

mean gestational age was 38.8 weeks \pm 1.42 weeks. The birth weight was between 1940 and $5285 \mathrm{~g}$ and the mean weight was $3286 \mathrm{~g} \pm 589.6 \mathrm{~g}$. The mean Apgar scores were 8.7, 8.8 and 8.9 at first, fifth and tenth minutes respectively. The mean time of transfer was 9 hours and it ranged between 1 and 159 hours. The average length of stay in the NICU was 5 days and it ranged between 1 and 78 days. The longer period of stay was related to neonatal abstinence syndrome which required longer treatment. 350 infants $(56 \%)$ were male and 275 were females (44\%). 381 infants were delivered via normal spontaneous vaginal delivery (NSVD) (61\%) and 244 via cesarean section (C-section) (39\%). The demographic characteristics are summarized in Table 1. Figure 1 shows transfer results categorized by system and in table 2 we list all the reasons for transfer.

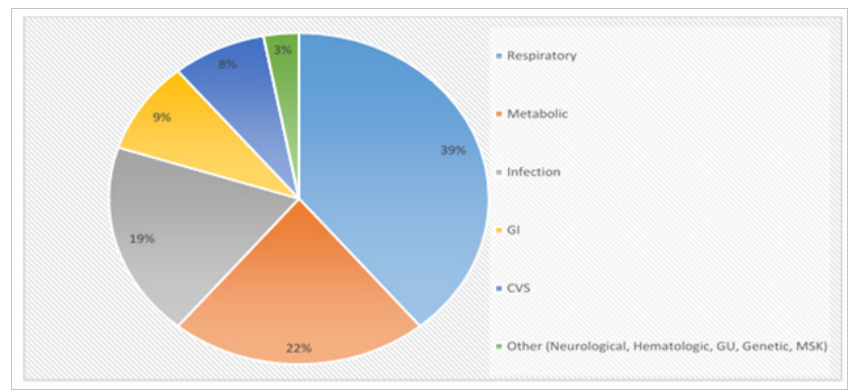

Figure I Transfer results by system.

Table I Demographic characteristics

\begin{tabular}{|c|c|c|c|}
\hline & & Min - max & $\begin{array}{l}\text { Mean } \pm \text { standard } \\
\text { deviation }\end{array}$ \\
\hline Gestational age ( & veeks) & $34-42$ & $38.8 \pm 1.4$ \\
\hline Birth weight (gran & & $1940-5285$ & $3286 \pm 589.6$ \\
\hline Apgar score at In & & $3-9$ & $8.7 \pm 0.8$ \\
\hline Apgar score at $5 n$ & & $5-9$ & $8.8 \pm 0.3$ \\
\hline Apgar score at 10 & $\min$ & $7-9$ & $8.9 \pm 0.9$ \\
\hline Hour of transfer & (hours) & $1-159$ & 9 \\
\hline Length of stay (da & & I - 78 & 5 \\
\hline & & Number & Percentage \% \\
\hline & $<24 h$ & 443 & 70.88 \\
\hline Hour of transfer & $24-48 h$ & 106 & 16.96 \\
\hline & $\geq 48 \mathrm{~h}$ & 76 & 12.16 \\
\hline Deliverv tyoe & Nsvd & 381 & 60.96 \\
\hline Detive ty суре & C-section & 244 & 39.04 \\
\hline & Hispanic & 379 & 60.64 \\
\hline Race & African american & 237 & 37.92 \\
\hline & Other & 9 & 1.44 \\
\hline Gender of baby & Female & 275 & 44 \\
\hline & Male & 350 & 56 \\
\hline
\end{tabular}

Table 2 Reasons for transfer

\begin{tabular}{ll}
\hline Reason & Result \\
\hline & Transient Tachypnea of Newborn (TTNB) I I3 (I8\%) \\
& Respiratory Distress of Newborn 89 (I4\%) \\
& Meconium Aspiration Syndrome 27 (4\%) \\
Respiratory 247 (39\%) & Pneumonia I0 (I\%) \\
& Pneumothorax 3 (0.4\%) \\
& Pneumomediastinum 2 (0.3\%) \\
& Apnea 2 (0.3\%) \\
& Desaturation I (0.1\%) \\
\hline Reason & Result \\
\hline
\end{tabular}

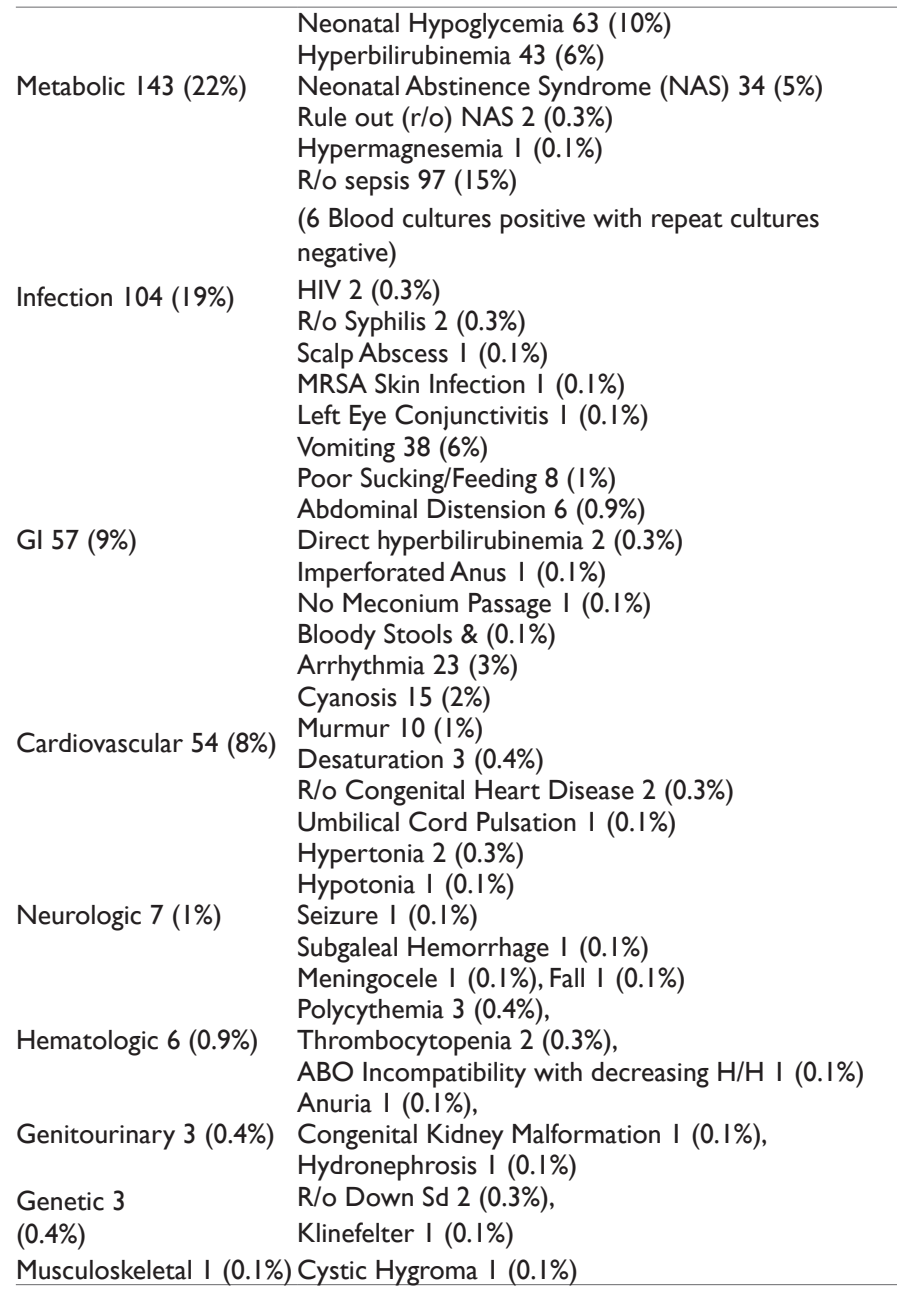

Sixteen out of $625(2.6 \%)$ infants required a transfer to a tertiary care center (TCC) and the descriptions are listed in table 3 and all infants did well with a good outcome. These were all identified in the WBN and the full work up was performed in the NICU with the appropriate consultant assessment before the transfer to the TCC. One infant out of 625 died in our own hospital before transfer to TCC due to a severe congenital heart disease (severe pulmonary stenosis).

\section{Discussion}

Our institution is a level III perinatal center with an active residency program that provides total care for all infants under close supervision by neonatal and perinatal attendings. A level III perinatal center is a hospital with a NICU organized with personnel and equipment to provide continuous life support and comprehensive care for extremely high-risk newborn infants and those with complex and critical illness. ${ }^{1}$ Clinical criteria to identify newborns at risk of instability during extrauterine transition of life in the WBN requires collaborative nursing and medical management in assessing and identifying the clinical condition of the infant. ${ }^{2}$ The decision to admit low risk infants (late preterm, infant of diabetic mother, preterm premature rupture of membranes, infants of toxemic mothers and infants with minor congenital anomalies) to the WBN was decided by the on call neonatal attending. The criteria on which unit to admit an infant was not clearly defined, so it was at the discretion of each attending to keep those infants in the WBN after they were assessed 
in the labor and delivery room and were in stable condition. Most low risk infants were admitted to the WBN to facilitate mother infant bonding, initiate breastfeeding, to keep the infant with the mother and to decrease unnecessary overcrowding in the NICU while providing continuous medical and nursing care in the WBN. $625(16 \%)$ of our total 3860 NICU admissions are from transfers while our NICU average census remained the same throughout the study period. Of those transfers shown in Table 2, respiratory problems were the most common (39\%), of which the most common was transient tachypnea of newborn (TTNB), while the least common reasons for transfer were neurologic, hematologic, genitourinary, genetic and musculoskeletal. Nighty seven infants $(15 \%)$ were transferred to rule out sepsis, of which 6 infants had positive blood cultures (three with group $B$ streptococcus, one Staphylococcus Aureus, one Escherichia Coli and one Streptococcus Mitis), those cases are currently reviewed. All these infants did well in our hospital except one who died from a critical heart disease condition before transfer to TCC. Among the sixteen infants transferred out to TCC shown in Table 3, ten were due to a critical congenital heart disease. All these infants did well in the TCC.

Table 3 Transfer to tertiary care center

\begin{tabular}{|c|c|c|c|c|c|}
\hline $\begin{array}{l}\text { Birth Weight } \\
\text { (grams) }\end{array}$ & $\begin{array}{l}\text { Gestational Age } \\
\text { (weeks) }\end{array}$ & $\begin{array}{l}\text { Hour of Transfer } \\
\text { to NICU }\end{array}$ & $\begin{array}{l}\text { Reason for Transfer to } \\
\text { NICU }\end{array}$ & Diagnosis in NICU & $\begin{array}{l}\text { Age at Transfer to Tertiary } \\
\text { Care Center (days) }\end{array}$ \\
\hline 2345 & 37 & 24 & Vomiting & $\begin{array}{l}\text { Obstruction gastric antrum small bowel } \\
\text { loop on upper gastrointestinal series }\end{array}$ & I \\
\hline 3990 & 39 & 2 & TTNB & $\begin{array}{l}\text { ENT evaluation to rule out } \\
\text { laryngotracheomalacia }\end{array}$ & 8 \\
\hline 2940 & 40 & 3 & 4/6 Pansystolic Murmur & Interrupted aortic arch on echocardiogram & 3 \\
\hline 2500 & 38 & 30 & Cyanosis & Tetralogy of Fallot & 2 \\
\hline 3090 & 37 & 8 & 4/6 Pansystolic Murmur & Interrupted aortic arch on echocardiogram & 2 \\
\hline 3475 & 38 & I & Murmur & $\begin{array}{l}\text { Tricuspid and Pulmonary atresia on } \\
\text { echocardiogram }\end{array}$ & I \\
\hline 3695 & 39 & 2 & Murmur & Total anomalous pulmonary venous return & 1 \\
\hline 3270 & 38 & 29 & Respiratory Distress & Taussing-Bing anomaly on echocardiogram & 2 \\
\hline 4030 & $4 I$ & 25 & Cystic Hygroma & $\begin{array}{l}\text { Bilateral fluid like cystic collections in soft } \\
\text { tissue of neck and skull base }\end{array}$ & 2 \\
\hline 3460 & 40 & 28 & Cyanosis & Transposition of great vessels & 1 \\
\hline 3355 & 40 & 6 & Murmur & $\begin{array}{l}\text { Tricuspid and Pulmonary atresia on } \\
\text { echocardiogram }\end{array}$ & I \\
\hline 3310 & 38 & 4 & Respiratory Distress & Total anomalous pulmonary venous return & I \\
\hline 3020 & 35 & 43 & Vomiting & Dilated loops on abdominal X-ray & 4 \\
\hline 2525 & 36 & 3 & $\begin{array}{l}\text { Congenital Kidney } \\
\text { Malformation }\end{array}$ & $\begin{array}{l}\text { Enlarged hyperechoic kidneys without } \\
\text { hydronephrosis on renal ultrasound }\end{array}$ & 3 \\
\hline 2705 & 39 & 34 & Desaturation & $\begin{array}{l}\text { Severe neonatal Ebstein anomaly } \\
\text { with pulmonary hypertension on } \\
\text { echocardiogram }\end{array}$ & 3 \\
\hline 3625 & 40 & 35 & $\begin{array}{l}\text { Failure to Pass Meconium } \\
\text { and Bilious Vomiting }\end{array}$ & $\begin{array}{l}\text { Distal small bowel obstruction on } \\
\text { abdominal X-ray }\end{array}$ & I \\
\hline
\end{tabular}

\section{Conclusion}

A careful, thorough evaluation of the infants transferred from the WBN to the NICU will help to identify the risk of infants who later require further care in the NICU. Keeping the infant in WBN will facilitate early mother infant bounding and detection of common problems by the medical and nursing teams. The findings of our research for this improvement project was presented to the residents to help them improve the monitoring management of low risk infants in the WBN. All infants met the criteria for admission to WBN and none had any signs and symptoms that required NICU admission. Theses infants met the criteria for early recognition and timely transfer to NICU for further care. When assessing an infant in WBN for a transfer in NICU, special attention should be given for assessment of maternal and infant medical issues which threaten the neonatal outcome with particular attention to cardiorespiratory status.

\section{Conflicts of Interest}

The authors declare no potential conflicts of interest with respect to the research, authorship, and/or publication of this article.

\section{Acknowledgements}

We would like to thank the former residents who helped manage the patients during their stay in the NICU.

\section{References}

1. Stark AR. Levels of Neonatal Care. Pediatrics. 2004;114(5):1341-1347.

2. Pfeiffer Judith, Keeler Denise. Normal Newborn Nursery - Neonatal Intensive Care Unit: What's in Between? Journal of Obstetric, Gynecologic \& Neonatal Nursing. 2012;41:S46. 